\title{
Emotionality Activity Sociability and Impulsivity (EASI) Survey: Psychometric properties and assessment biases of the Japanese version
}

\author{
Toshinori Kitamura ${ }^{1,2}$, Yukiko Ohashi ${ }^{1}$, Mariko Minatani ${ }^{1,3}$, Megumi Haruna $^{3}$, \\ Mikihiko Murakami ${ }^{4}$, Yoshitaka Goto ${ }^{4}$ \\ ${ }^{1}$ Kitamura Institute of Mental Health Tokyo, Tokyo, Japan \\ ${ }^{2}$ Department of Psychiatry, Nagoya University Graduate School of Medicine \\ ${ }^{3}$ Department of Midwifery and Women's Health, Graduate School of Medicine, University of Tokyo \\ ${ }^{4}$ Kumamoto Paediatric Associations, Kumamoto, Kumamoto, Japan
}

\section{Email address:}

kitamura@institute-of-mental-health.jp (T. Kitamura)

\section{To cite this article:}

Toshinori Kitamura, Yukiko Ohashi, Mariko Minatani, Megumi Haruna, Mikihiko Murakami, Yoshitaka Goto. Emotionality Activity Sociability and Impulsivity (EASI) Survey: Psychometric Properties and Assessment Biases of the Japanese Version. Psychology and Behavioral Sciences. Vol. 3, No. 4, 2014, pp. 113-120. doi: 10.11648/j.pbs.20140304.12

\begin{abstract}
Background: The EASI Survey, a 20-item parent report, was one of the first instruments developed to measure children's temperament. Methods: We performed an exploratory factor analysis (EFA) of the EASI items in a randomly halved population of Japanese fathers $(n=237)$ and mothers $(n=412)$ of children under four years of age. The factor structure was cross-validated by a confirmatory factor analysis (CFA). Then, parents' assessments of each temperament were regressed on the other parents' assessments and then on a variety of intrapersonal and interpersonal variables related to the assessor parents. Results: An EFA yielded a two-factor structure but a four-factor structure according to the original report showed better fit with the data. The new four-factor model (excluding items with low factor loadings) showed in a CFA acceptable goodness-of-fit with the data. This four subscales showed moderate internal consistency. Parental assessment of the EASI subscales was explainable by the assessment rated by the other parent. After controlling it, parents with depression, anger, and less caring attitudes were more likely to rate their child's Emotionality and Impulsivity higher than their partners. Conclusions: The EASI Survey may be applicable to a Japanese non-clinical child population.
\end{abstract}

Keywords: Temperament, Assessment, Parental Personality, Anger, Bond to Child

\section{Introduction}

Individual differences of infants and toddlers have been a major research issue in child nursing as well as psychology and psychiatry. Among the wide range of available temperament questionnaires, the EASI Survey [1] is one of the first instruments used in nursing research settings. This is a 20-item questionnaire with five items for each of four temperament domains: Emotionality, Activity, Sociability, and Impulsivity. Buss and Plomin [1] examined the factor structure of the 20 EASI Survey items and reported the inheritance of the domains through a twin study [2]. The first aim of this preliminary report concerns the psychometric properties of the EASI Survey, particularly its factor structure, in a Japanese non-clinical infant and toddler population.

The EASI is usually rated by parents. Although parents can provide valuable information about a child's behavioural characteristics, fathers and mothers are not always in agreement [3]. Their assessment is not always without systematic bias. Systematic distortion of parental reports of children's behaviour may stem from recent stressful life events [4], anticipating the baby during pregnancy [5], and maternal depression [6-10] (but see opposing evidence $[11,12]$, and discussion [13] ). A second aim of this study was to examine the extent to which parental assessment of each of the EASI Survey subscales is biased by a variety of variables. We examined the effect that parents' social desirability had on the assessment of their child's temperament. Then, we examined the influence of parents' intrapersonal 
characteristics. They include parental depression and anxiety, personality, and anger and anger expression. Parental assessment of the child's temperament may also be biased by their attitudes towards the child. Because there was no gold standard to the assessment of child's temperament, we posited tentatively that the other parent's assessment (for example the mother's) should be used as a gold standard against which the parent's assessment (in this case the father's) would be evaluated in terms of the degree to which it is biased by psychological variables.

\section{Methods}

\subsection{Participants}

The present survey was planned and conducted in collaboration with the Kumamoto Paediatric Association in 2002. To our request to the members of the Association, 20 clinics out of all the 41 clinics agreed to participate in the study. All the participating paediatric clinics provided generalized child care. None of them was specialised for particular paediatric conditions. Children with serious diseases are referred to specialised institutions such as university hospitals. Hence, most of the children in this study were unlikely to be suffering from serious medical conditions. Paediatricians handed the questionnaire to the parent(s) of each child aged less than four years who visited the clinic. Thus, the present sample was convenient. The parents were asked to enter the study and, if they agreed to do so, they were given another questionnaire so that each partner had a copy. The fathers and mothers were asked to fill out the questionnaire independently. The total number of families who participated in the survey was 447 . However, only 247 fathers and 434 mothers returned completed questionnaires, and only in 234 cases did both parents return completed questionnaires. The mean (SD) age of the fathers and mothers was 33.4 (5.5) and 31.5 (5.4) years, respectively. The fathers were significantly older than the mothers $(p<.001)$. The mean age (SD) of the children was $1.7(1.1)$ years. There were 225 boys $(50.0 \%)$ and 209 girls $(46.8 \%)$. The gender was unknown for the remaining 13 children $(2.8 \%)$.

Because we were interested in the factor structure the EASI scale in the first part of this study, we used the questionnaire data from the fathers $(n=237)$ and mothers ( $n$ $=412$ ) who filled in all 20 EASI items. The fathers' and mothers' data were combined and used for the analyses of the factor structure of the EASI $(n=237+412=649)$. For the analyses of the biases of the EASI assessment, we used only the data where both parents responded to the questionnaire (234 couples).

\subsection{Measurements}

\subsubsection{The EASI Survey}

The EASI Survey [1] was translated into Japanese by one of us (TK) following permission from the original authors. It consists of 20 items measuring four temperament dimensions. Each item was rated on a 5-point scale: from 0 (a little) to 4 (a lot). The scaling of the original EASI Survey was from 1 to 5 but we changed it to from 0 to 4 so that the possible score of each dimension would range from 0 to 20 . For the examination of the factor structure of the EASI, we deleted all cases in which at least one value out of the 20 EASI items was missing. However, when examining biases of the EASI scoring, we substituted a missing value with a mean of the item if the participant replied to at least 18 items $(80 \%$ of the total).

\subsubsection{Social Desiability of Parents}

In order to measure social desirability of parents, we used the Social Desirability Scale (SDS) $[14,15]$. The original SDS consisted of 33 items, but was reduced to 10 items to suit the Japanese population. Respondents used a 5-point scale (from 0 to 4 ) to rate each item, thus the total SDS score could range from 0 to 40 .

\subsubsection{Depression and Anxiety of Parents}

We used the Hospital Anxiety and Depression Scale (HADS) $[16,17]$ to measure mood and cognitive symptoms of depression and anxiety of parents. The HADS consists of 14 items; the Depression and Anxiety subscales each include seven items on a 4-point scale ( 0 to 3 ). Missing values of the HADS items were substituted with the mean of the item only for those cases in which fewer than three items $(20 \%$ of the total) were missing.

\subsubsection{Parental Personality}

As the measure of parental personality, we used the Japanese version of the Temperament and Character Inventory (TCI) [18], a self-report measure of personality based on a seven-factor model of temperament and character. Temperament consists of four heritable dimensions that are manifested early in life: Novelty Seeking (NS), Harm Avoidance (HA), Reward Dependence (RD), and Persistence (PS) (which emerges from RD). These temperament dimensions are deemed to be determined genetically and the first three correlate with dopaminergic, serotonergic and noradrenergic activity, respectively. Character was thought of as weakly heritable but a recent study has demonstrated that it is almost equally heritable as temperament [19]. Character consists of three dimensions, which mature in adulthood. They include Self-directedness (SD), Co-operativeness (CO), and Self-transcendence (ST). The character dimensions are hypothesised to be determined more by environmental factors. We used the 125-item short version of the TCI. We added five additional $\mathrm{P}$ items because their number was relatively small. The original dichotomous scale was changed into a 4-point scale [20] in this study; each item was rated from 0 ('strongly disagree') to 3 ('strongly agree'). Missing values of the TCI items were substituted with the mean of the item only for those cases in which fewer than 27 items (20\% of the total) were missing.

\subsubsection{Anger trait and Anger Expression of Parents}

Anger trait and anger expression of parents were rated by the State-Trait Anger Expression Inventory (STAXI) [21, 
22]. This is a self-report which measures the intensity of anger as an emotional state and the disposition to experience angry feelings as a personality trait. The original STAXI consisted of 44 items yielding five scales - State Anger (10 items), Trait Anger (10 items), Anger-In (eight items), Anger-Out (eight items), and Anger-Control (eight items). However, for the sake of brevity we excluded all State Anger items and reduced the number of items of Anger-In, Anger-Out, and Anger-Control to three items each. Missing values of the STAXI items were substituted with the mean of the item only for those cases in which fewer than four items ( $20 \%$ of the total) were missing.

\subsubsection{Parental Rearing Styles}

Current parental rearing styles were rated by the Parental Bonding Instrument (PBI) [23, 24]. The PBI is a 25-item measure with a 4-point scale ( 0 to 3 ) to assess retrospectively how an individual perceived their father and mother's parenting before they were 16 years old. In this study, however, we asked participating parents to rate their own current rearing styles by using the PBI. The third person was modified to the second person and the past tense was modified to the present tense in each PBI item. In addition, we asked them to rate their partner's current rearing styles towards their child. Hence, there were two sources of information on the rearing styles of each parent: one from the parent him- or herself and the other from the partner. Care items (12 items) relate to a parenting style that may range from coldness, indifference and neglect, to affection, emotional warmth, empathy, and reciprocity. Overprotection items (13 items) define a dimension ranging from parental control and overprotection, intrusion and infantilization to parental allowance, independence, and the development of autonomy. Missing values of the PBI items were substituted with the mean of the item only for cases in which fewer than six items $(20 \%$ of the total) were missingtemplate is used to format your paper and style the text. All margins, column widths, line spaces, and text fonts are prescribed; please do not alter them. You may note peculiarities. For example, the head margin in this template measures proportionately more than is customary. This measurement and others are deliberate, using specifications that anticipate your paper as one part of the entire publication, and not as an independent document. Please do not revise any of the current designations.

\subsection{Ethical Consideration}

This research project was approved by the Ethical Committee of Kumamoto University Graduate School of Medical Sciences.

\subsection{Statistical Analyses}

We randomly divided the participants who filled in all EASI items into two groups. For the first group $(n=328$; 116 fathers and 212 mothers) we performed an exploratory factor analysis (EFA). Because inclusion of items with a low base rate in an EFA may lead to distorted structure, we planned to exclude items from analyses if their mean was less than 0.4 , which is one-tenth of the range (four) added to the lowest score (zero). All factors were considered to be dependent upon each other. Hence, the factor solution was sought via PROMAX rotation, which is a diagonal rotation. The number of factors was determined by the scree test [25]. Because we were interested in the refinement of the EASI scale so as to be suitable for a Japanese population, we excluded EASI items that showed a factor loading of less than .4 on the factor that corresponded to the original category. Thus, for example, if an item that was originally categorised as belonging to Activity showed a factor loading of less than .4 on a factor on which other Activity items showed a factor loading of greater than .4 , this item was excluded from further analyses.

In order to confirm the stability of the factor structures obtained from the above EFAs, we performed a series of confirmatory factor analyses (CFAs) on the EASI items in the second group of parents (121 fathers and 200 mothers). In order to improve the model's fit with the data, modification indices were used and new covariance estimates were consecutively added. We paid most attention to insuring that the suggested modification by the indices made theoretical or common sense [26]. The fit of each model with the data was examined in terms of chi-squared (CMIN), comparative fit index (CFI), and root mean square error of approximation (RMSEA). According to conventional criteria, a good fit would be indicated by $\mathrm{CMIN} / \mathrm{df}<2$, CFI $>0.97$, and RMSEA $<0.05$, while an acceptable fit would correspond to CMIN/df $<3$, CFI $>0.95$, and RMSEA $<0.08$ [27]. The Akaike Information Criterion (AIC) was used to compare different models; a model with an AIC at least two points lower than second model is regarded as the superior one.

In order to assess the possible biases of different variables on the EASI ratings, we regressed the parent's assessment of each of the EASI dimensions derived from EFA and CFA first on the parent's age, then on the other parent's assessment of the dimension, and then on the predictor variables. The predictors were entered separately as a group.

All statistical analyses were conducted using the SPSS version 14.0 and Amos 6.0.

\section{Results}

\subsection{Factor Structure of the EASI Items}

In none of the EASI items in the first group of parents was the mean score less than 0.4, and thus all the EASI items were subjected to an EFA. The scree plot clearly indicated a two-factor model. High factor loadings $(>.4)$ were shown on the first factor by the EASI items originally categorised as belonging to Emotionality, Activity, and Impulsivity (Table 1). On the other hand, high factor loadings were shown on the second factor by the EASI items originally categorised as belonging to Sociability. Some items, however, did not show a factor loading higher than .4: thus, "Is easily frightened" (Emotionality item), "Is easy-going or happy-go-lucky" 
(Emotionality item, reversed), "Prefers quiet games such as colouring or block play to more active games" (Activity item, reversed), and "Tends to be shy" (Sociability item, reversed) showed a low factor loading on the first factor. An Activity item, "Is always on the go", showed a high factor loading on the second factor (on which other Activity items did not have high factor loadings) but its factor loading on the first factor was nearly $.4(.36)$. Thus this item was retained as belonging to the two latent factors. As a result, there remained 14 EASI items.

Table 1. Means and SDs of the EASI items and the factor structure

\begin{tabular}{|c|c|c|c|c|c|}
\hline \multirow{2}{*}{ No } & \multirow{2}{*}{ item } & \multirow{2}{*}{$\begin{array}{l}\text { Original } \\
\text { category }\end{array}$} & \multirow{2}{*}{ Mean (SD) } & \multicolumn{2}{|l|}{ Factors } \\
\hline & & & & I & II \\
\hline 1 & Cries easily & $\mathrm{E}$ & $2.1(1.1)$ & .40 & -.41 \\
\hline 5 & Has a quick temper & $\mathrm{E}$ & $2.1(1.1)$ & .69 & .08 \\
\hline 9 & Gets upset quickly & $\mathrm{E}$ & $2.0(1.1)$ & .76 & -.04 \\
\hline 13 & Is easily frightened & $\mathrm{E}$ & $1.6(1.1)$ & .28 & -.45 \\
\hline 17 & Is easy-going or happy-go-lucky & $\mathrm{E}^{*}$ & $1.8(0.9)$ & .03 & -.31 \\
\hline 2 & Is off and running as soon as he/she wakes up in the morning & A & $2.8(1.1)$ & .10 & .30 \\
\hline 6 & Is always on the go & A & $2.9(1.1)$ & .36 & .43 \\
\hline 10 & Cannot sit still long & A & $2.4(1.1)$ & .66 & .16 \\
\hline 14 & Prefers quiet games such as colouring or block play to more active games & $A^{*}$ & $2.3(0.9)$ & .12 & .29 \\
\hline 18 & Fidgets at meals and similar occasions & A & $2.4(1.2)$ & .49 & .02 \\
\hline 3 & Makes friends easily & $\mathrm{S}$ & $2.4(0.9)$ & .01 & .65 \\
\hline 7 & Likes to be with others & $\mathrm{S}$ & $3.5(0.8)$ & .11 & .64 \\
\hline 11 & Tends to be shy & $\mathrm{S}^{*}$ & $1.7(1.1)$ & -.11 & .36 \\
\hline 15 & Is independent & $\mathrm{S}$ & $2.5(0.9)$ & -.11 & .40 \\
\hline 19 & Prefers to play by him/herself rather than with others & $\mathrm{S}^{*}$ & $2.6(0.9)$ & .00 & .43 \\
\hline 4 & Earning self-control is difficult for him/her & I & $1.4(1.0)$ & .51 & -.22 \\
\hline 8 & Tends to be impulsive & I & $2.0(1.0)$ & .76 & .09 \\
\hline 12 & Gets bored easily & I & $2.0(1.0)$ & .59 & -.12 \\
\hline 16 & Learns temptation easily & $I^{*}$ & $2.2(0.8)$ & .21 & -.06 \\
\hline \multirow[t]{2}{*}{20} & Goes from toy to toy quickly & I & $2.2(1.0)$ & .58 & .08 \\
\hline & Total variance explained & & & $18.6 \%$ & $11.2 \%$ \\
\hline
\end{tabular}

Factor loadings greater than .4 are in bold. Asterisks indicate reverse items.

These 14 EASI items were then subjected to a CFA. Here we posited a two-factor model. We set two latent factors: "Emotionality/Impulsivity/Activity" and "Sociability" (Fig. 1). The item "Is always on the go" was posited to belong to the two latent factors. The model fit the data acceptably: $\mathrm{CMIN} / \mathrm{df}=2.2, \mathrm{CFI}=0.908$, and $\mathrm{RMSEA}=0.061$.

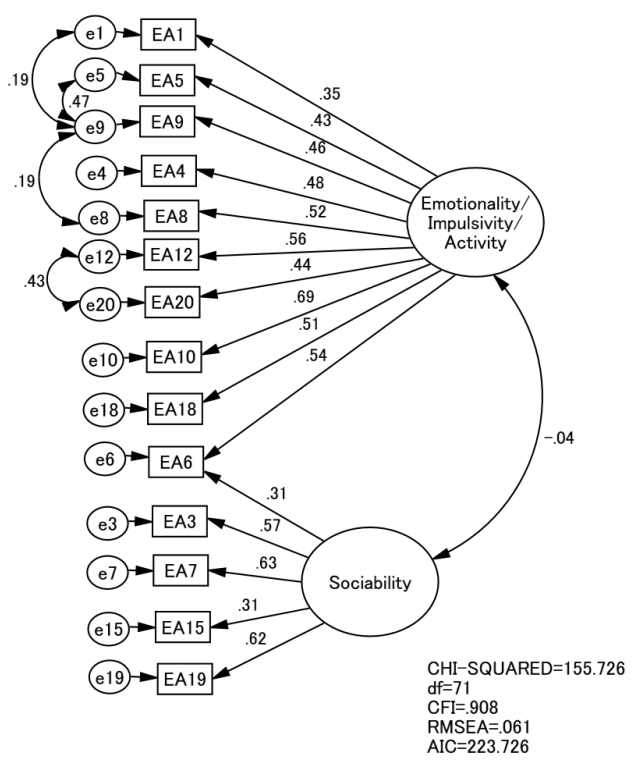

The number attached to each indicator variable represents the IESI item number. See Table 1 for the content of each EASI item.

Fig. 1. Confirmatory factor analysis of the Japanese EASI Survey in a two-factor model

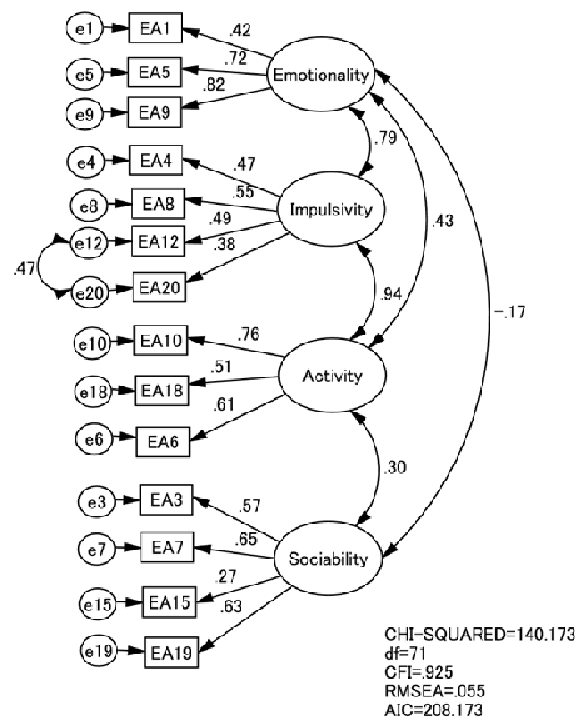

The number attached to each indicator variable represents the IESI item number. See Table 1 for the content of each EASI item.

Fig. 2. Confirmatory factor analysis of the Japanese EASI Survey in a four-factor model

Because Buss and Plomin [1] proposed a four-factor structure, we tested the feasibility of such a model using the above 14 items (Fig. 2). In this model, we treated the item "Is always on the go" as belonging to Activity as suggested by the original study. Such a CFA model fit the data acceptably: $\mathrm{CMIN} / \mathrm{df}=1.97, \mathrm{CFI}=0.925$, and $\mathrm{RMSEA}=$ 0.055 . AIC was better for the 4 - rather than 2-factor models. 
We chose the 4-factor model (Fig. 2) as the final model because of correspondence to the original four-factor model.

We calculated the four subscales of the EASI by adding the scores of items belonging each of the four factors identified by CFA-Emotionality (three items), Activity (three items), Sociability (four items), and Impulsivity (four items). They showed moderate internal consistency expressed as Cronbach's $\alpha$ : Emotionality (.72 for fathers and .60 for mothers), Activity (.56 for fathers and .58 for mothers), Sociability (.51 for fathers and .56 for mothers), and Impulsivity (fathers and .62 for mothers).

\subsection{Effects of Social Desirability and Intra- and Inter-Personal Variables on the EASI Scores}

As expected, a series of regression analyses on the father's assessment of each EASI dimension showed that the father's assessment of an EASI dimension was explained by the mother's assessment of the same dimension as well as the father's age. After controlling for these variables, regression analyses also showed that (1) the tendency to respond in a socially desirable manner was associated with lower Emotionality score; (2) HADS Depression was slightly associated with greater Emotionality score; (3) NS was associated with greater Emotionality and Impulsivity scores, RD with lower of Emotionality and Impulsivity scores, PS with greater Emotionality score, and SD with lower Activity and Impulsivity scores; (4) Trait Anger was associated with greater Emotionality and Impulsivity scores and Anger-In with greater Emotionality score; and (5) self-assessment of Care was associated with lower Emotionality and greater Sociability scores, self-assessment of Overprotection with greater Emotionality scores, and partner's assessment of Care with lower of Impulsivity score (Table 2).

Table 2. Prediction of fathers' assessment of the Japanese EASI subscales by different psychological variables after controlling for mothers' assessment and fathers'age

\begin{tabular}{|c|c|c|c|c|c|c|c|c|}
\hline \multirow[b]{2}{*}{ Predictor variables } & \multicolumn{2}{|l|}{ Emotionality } & \multicolumn{2}{|l|}{ Activity } & \multicolumn{2}{|l|}{ Sociability } & \multicolumn{2}{|l|}{ Impulsivity } \\
\hline & $\begin{array}{l}\text { R2 increase } \\
(d f)\end{array}$ & $\begin{array}{l}\text { Standardised } \\
\beta\end{array}$ & $\begin{array}{l}\text { R2 increase } \\
(d f)\end{array}$ & $\begin{array}{l}\text { Standardised } \\
\beta\end{array}$ & $\begin{array}{l}\text { R2 increase } \\
(d f)\end{array}$ & $\begin{array}{l}\text { Standardised } \\
\beta\end{array}$ & $\begin{array}{l}\text { R2 increase } \\
(d f)\end{array}$ & $\begin{array}{l}\text { Standardised } \\
\beta\end{array}$ \\
\hline Social desirability & $\begin{array}{l}.054 * * * \\
(1,212)\end{array}$ & & $.002(1,212)$ & & $.000(1,212)$ & & $.009(1,212)$ & \\
\hline SDS & & $-.235 * * *$ & & .041 & & .018 & & -.097 \\
\hline Dysphoric mood & $\begin{array}{l}.077 * * * \\
(2,210)\end{array}$ & & $.020(2,210)$ & & $.003(2,210)$ & & $.021(2,210)$ & \\
\hline HADS Depression & & $.202 *$ & & -.057 & & -.055 & & .095 \\
\hline HADS Anxiety & & .100 & & $.171 *$ & & -.057 & & .062 \\
\hline Personality & $\begin{array}{l}.106 * * * \\
(7,204)\end{array}$ & & $.043(7,204)$ & & $.038(7,204)$ & & $\begin{array}{l}.130 * * * \\
(7,204)\end{array}$ & \\
\hline Novelty Seeking & & $.194 * *$ & & .077 & & .120 & & $.195 * *$ \\
\hline Harm Avoidance & & .082 & & -.010 & & -.064 & & .068 \\
\hline Reward Dependence & & $-.172 *$ & & -.120 & & -.030 & & $-.207 * *$ \\
\hline Persistence & & $.178 *$ & & .138 & & -.074 & & .044 \\
\hline Self-directedness & & $-.178 *$ & & $-.183 *$ & & .072 & & $-.197 *$ \\
\hline Cooperativeness & & .098 & & .068 & & .106 & & .042 \\
\hline Self-transcendence & & .083 & & -.043 & & .029 & & .034 \\
\hline $\begin{array}{l}\text { Anger trait and anger } \\
\text { expression }\end{array}$ & $\begin{array}{l}.098 * * * \\
(4,212)\end{array}$ & & $.023(4,212)$ & & $.015(4,212)$ & & $.057 * *$ & \\
\hline Trait Anger & & $.275 * * *$ & & $.152 *$ & & -.098 & & $.218 * *$ \\
\hline Anger-In & & $.131 *$ & & .050 & & -.077 & & .041 \\
\hline Anger-Out & & -.050 & & -.097 & & -.056 & & .019 \\
\hline Anger Control & & .107 & & .066 & & -.027 & & .038 \\
\hline $\begin{array}{l}\text { Parental rearing } \\
\text { styles }\end{array}$ & $\begin{array}{l}.090 * * * \\
(4,208)\end{array}$ & & $.037 *(4,208)$ & & $\begin{array}{l}.050 * * \\
(4,208)\end{array}$ & & $\begin{array}{l}.053 * * \\
(4,208)\end{array}$ & \\
\hline $\begin{array}{l}\text { Self-assessment of } \\
\text { Care }\end{array}$ & & $-.242 * *$ & & -.121 & & $.164 *$ & & -.098 \\
\hline $\begin{array}{l}\text { Self-assessment of } \\
\text { Overprotection }\end{array}$ & & $.150 *$ & & -.039 & & -.118 & & .079 \\
\hline $\begin{array}{l}\text { Spousal assessment } \\
\text { of Care }\end{array}$ & & .055 & & -.067 & & -.105 & & $-.153 *$ \\
\hline $\begin{array}{l}\text { Spousal assessment } \\
\text { of Overprotection }\end{array}$ & & -.051 & & -.125 & & -.074 & & -.103 \\
\hline
\end{tabular}

$* p<.05 ; * * p<.01 ; * * * p<.001 \mathrm{R}^{2}$ increases in parental age and the other parent's assessment of the dimension are not shown.

As in fathers, a series of regression analyses on the mother's assessment of each EASI dimension showed that the mother's assessment of an EASI dimension was explained by the father's assessment of the same dimension as well as the mother's age. After controlling for these variables, regression analyses also showed that (1) SDS scores did not explain all of the EASI scores; (2) HADS Depression was associated with greater Emotionality and lower Sociability scores; (3) RD was associated with lower Impulsivity score, and SD with lower Emotionality score; 
and (4) self-assessment of Care was associated with lower Emotionality and Impulsivity score, and self-assessment of
Overprotection with greater Activity, lower Sociability and greater Impulsivity scores (Table 3).

Table 3. Prediction of mothers' assessment of the Japanese EASI subscales by different psychological variables after controlling for fathers' assessment and mothers'age

\begin{tabular}{|c|c|c|c|c|c|c|c|c|}
\hline \multirow[b]{2}{*}{ Predictor variables } & \multicolumn{2}{|l|}{ Emotionality } & \multicolumn{2}{|l|}{ Activity } & \multicolumn{2}{|l|}{ Sociability } & \multicolumn{2}{|l|}{ Impulsivity } \\
\hline & $\begin{array}{l}\text { R2 increase } \\
\text { (degree of } \\
\text { freedom) }\end{array}$ & $\begin{array}{l}\text { Standardised } \\
\beta\end{array}$ & $\begin{array}{l}\text { R2 increase } \\
\text { (degree of } \\
\text { freedom) }\end{array}$ & $\begin{array}{l}\text { Standardised } \\
\beta\end{array}$ & $\begin{array}{l}\mathrm{R} 2 \text { increase } \\
\text { (degree of } \\
\text { freedom) }\end{array}$ & $\begin{array}{l}\text { Standardised } \\
\beta\end{array}$ & $\begin{array}{l}\mathrm{R} 2 \text { increase } \\
\text { (degree of } \\
\text { freedom) }\end{array}$ & $\begin{array}{l}\text { Standardised } \\
\beta\end{array}$ \\
\hline Social desirability & $.012(1,210)$ & & $.010(1,210)$ & & $.002(1,210)$ & & $.002(1,210)$ & \\
\hline SDS & & -.111 & & -.098 & & -.049 & & -.042 \\
\hline Dysphoric mood & $\begin{array}{l}.035 * \\
(2,216)\end{array}$ & & $.014(2,216)$ & & $.016(2,216)$ & & $.041 * *$ & \\
\hline HADS Depression & & $.188 *$ & & .002 & & $-.151 *$ & & .119 \\
\hline HADS Anxiety & & .000 & & .119 & & .091 & & .112 \\
\hline Personality & $\begin{array}{l}.091 * * \\
(7,211)\end{array}$ & & $.042(7,211)$ & & $.035(7,211)$ & & $\begin{array}{l}.094 * * * \\
(7,211)\end{array}$ & \\
\hline Novelty Seeking & & .131 & & .016 & & -.083 & & .071 \\
\hline Harm Avoidance & & .050 & & -.007 & & -.142 & & .053 \\
\hline Reward Dependence & & -.026 & & -.044 & & -.008 & & $-.191 * *$ \\
\hline Persistence & & .095 & & .003 & & .091 & & .090 \\
\hline Self-directedness & & $-.150 *$ & & -.085 & & -.017 & & -.131 \\
\hline Cooperativeness & & -.143 & & $-.141 *$ & & .033 & & -.049 \\
\hline Self-transcendence & & .035 & & .008 & & -.025 & & .053 \\
\hline $\begin{array}{l}\text { Anger trait and } \\
\text { anger expression }\end{array}$ & $.058(4,212)$ & & $.013(4,212)$ & & $.009(4,212)$ & & $.032(4,212)$ & \\
\hline Trait Anger & & $.200 *$ & & .004 & & .114 & & -.011 \\
\hline Anger-In & & .070 & & .045 & & -.022 & & $.199 * *$ \\
\hline Anger-Out & & .006 & & .051 & & -.100 & & -.070 \\
\hline Anger Control & & .000 & & .100 & & -.024 & & -.082 \\
\hline $\begin{array}{l}\text { Parental rearing } \\
\text { styles }\end{array}$ & $.028(4,205)$ & & $.034(4,205)$ & & $\begin{array}{l}.045^{*} \\
(4,205)\end{array}$ & & $.063 * *$ & \\
\hline $\begin{array}{l}\text { Self-assessment of } \\
\text { Care }\end{array}$ & & $-.160 *$ & & .009 & & .026 & & $-.189 * *$ \\
\hline $\begin{array}{l}\text { Self-assessment of } \\
\text { Overprotection }\end{array}$ & & .005 & & $.143 *$ & & $-.213 * *$ & & $.130 *$ \\
\hline $\begin{array}{l}\text { Spousal assessment } \\
\text { of Care }\end{array}$ & & .027 & & .033 & & -.035 & & .071 \\
\hline $\begin{array}{l}\text { Spousal assessment } \\
\text { of Overprotection }\end{array}$ & & .058 & & .104 & & -.003 & & .047 \\
\hline
\end{tabular}

$* p<.05 ; * * p<.01 ; * * * p<.001 \mathrm{R}^{2}$ increases in parental age and the other parent's assessment of the dimension are not shown.

\section{Discussion}

The EFA indicated a two-factor model of the EASI. One factor covered items originally categorised as belonging to Emotionality, Activity, or Impulsivity. These items reflect a child's intrapersonal traits. Another factor, which corresponded to the Sociability items, reflects the child's interpersonal relationships and the capacity to maintain them. The factor structure derived from this EFA was confirmed as robust in the CFA. It was clear that these two factors were strongly independent because there was virtually no covariance between them.

Although we found that the two-factor model fit the data acceptably, we were also interested in whether the original four-factor model would still fit our data in a Japanese population. Therefore, we examined the fitness of the model using four latent variables-Emotionality, Impulsivity, Activity, and Sociability - according to the original research [1] but with only the 14 items that remained after elimination following EFAs. This model fit with the data no less than did the two-factor model. It was even better. Therefore we propose use of the four subscales using the 14 items in studies in Japanese populations

Furthermore, it revealed positive covariances between Emotionality, Impulsivity, and Activity, but the covariance with Sociability differed. Thus, Emotionality showed a negative covariance with Sociability whereas Activity showed a positive covariance with Sociability. Lack of covariance between Emotionality/Impulsivity/Activity and Sociability in the two-factor model may be spurious because of mixture of positive and negative covariances between the factors in the four-factor model.

The results of regression analyses suggest that scores of children's Emotionality and Impulsivity are subject to assessment bias derived from parents' own emotions such as anger and depression. Parents who are high in NS and low in $\mathrm{RD}$ and SD are more likely to perceive their child as more emotional and impulsive. The same as the previous studies $[4,6-10,13,28,29]$, parents may psychologically "project" their own negative or hostile feelings onto a child, whose behavioural characteristics they then rate unfavourably. On the other hand, children's interpersonal traits such as 
Activity and Sociability were much less likely to be biased by parental variables.

Regarding biases of the EASI scores, it was only among fathers that social desirability influenced the EASI ratings. The SDS explained only $5 \%$ of the variance of the Emotionality assessment. This was not the case among mothers. Nursing reseachers and clinicians should be cautious these potential bias when interpreting the parental report of a child's temperament.

However, these attributes of parents explain only a small portion of the variance of each EASI dimension ranging between .01 and .11 for Emotionality, .01 and .04 for Activity, .0 and .05 for Sociability, and .0 and .13 for Impulsivity. Therefore possible biases derived from these parental attributes may be, if any, limited. We propose that EASI is a reliable and stable instrument, and may be applicable to a Japanese non-clinical child population.

\section{Conclusion}

In this study, we demonstrated that the Japanese EASI Survey can, after deletion of ambiguous items, provide a measure of the four temperament dimensions of children proposed in the original study. The four-factor structure was cross-validated. Researchers and clinicians should be cautious when interpreting the parental report of a child's temperament because of various sources of potential bias that are, however, not very likely to interfere with the assessment reliability.

\section{Acknowledgements}

We thank the cooperation of the following paediatricians for collecting the data: Tsuneyoshi Egami, M.D., Hisako Fujikawa, M.D., Akio Furuse, M.D., Yoshiko Hattori, M.D., Yogo Haraguchi, M.D., Kaneshige Iribe, M.D., Tsunehiro Kuwahara, M.D., Toshinari Maeda, M.D., Hiroshi Mitsubuchi, M.D., Toru Miyazaki, M.D., Yuji Mizumoto, M.D., Ryozaburo Seguchi, M.D., Yasushi Shimada, M.D., Shigeto Sugino, M.D., Keiichi Taku, M.D., Tekehiko Ueno, M.D., Kyoko Uramoto, M.D., Ken Watanabe, M.D.

\section{Conflict of Interests}

The authors have no conflict of interest regarding the publication of this paper.

\section{References}

[1] A. H. Buss and R. Plomin, A Temperament Theory of Personality Development. John Wiley, New York, NY, USA, 1975.

[2] R. Plomin, J. Kagan, R. N. Emde et al., "Genetic change and continuity from four-teen to twenty months: the MacArthur longitudinal twin study," Child Development, Vol. 64, no. 5, pp. 1354-1376, 1993.
[3] R. Leblanc and C. R. Reynolds, "Concordance of mothers' and fathers' ratings of children's behaviour," Psychology in the Schools, Vol. 26, no. 3, pp. 225-229, 1989.

[4] K. Räikkönen, A-K. Personen, K. Heinonen, N. Komsi, A-L. Järvenpää, and T. E. Strandberg, "Stressed parents: a dyadic perspective on perceived infant temperament," Infant and child development, Vol. 15, no. 1, pp. 75-87, 2006.

[5] C. J. Mebert, "Dimensions of subjectivity in parents' ratings of infant temperament," Child Development, Vol. 62, no. 2, pp. 352-361, 1991.

[6] T. Field, C. Morrow, and D. Adelstein, "Depressed mothers' perceptions of infant behaviour," Infant Behavior and Development, Vol. 16, pp. 99-108, 1993.

[7] S. Hart, T. Field, and M. Roitfarb, "Depressed mothers' assessment of their neonates' behaviors," Infant Mental Health Journal, Vol. 20, no. 2, pp. 200-210, 1999.

[8] E. Mick, S. L. Santangelo, and D. Wypij, "Impact of maternal depression on ratings of comorbid depression in adolescents with attention-deficit/hyperactivity disorder," Journal of the American Academy of Child and Adolescent Psychiatry, Vol. 39, no. 3, pp. 314-319, 2000.

[9] V. Panaccione, and R. Wahler, "Child behavior, maternal depression, and social coercion as factors in the quality of child care," Journal of Abnormal Child Psychology, Vol. 14, no. 2, pp. 263-278, 1986.

[10] E. A. Schaughency, and B. B. Lahey, "Mothers' and fathers' perceptions of child deviance: roles of child behavior, parental depression, and marital satisfaction," Journal of Consulting and Clinical Psychology, Vol. 53, no. 5, pp. 718-723, 1985.

[11] M. H. Boyle, and A. R. Pickles, "Influence of maternal depressive symptoms on ratings of childhood behaviour," Journal of Abnormal Child Psychology, Vol. 25, no. 5, pp. 407-412, 1997.

[12] M. G. Sayer, D. L. Streiner, and P. Baghurst, "The influence of distress on mothers' and fathers' reports of childhood emotional and behavioral problems," Journal of Abnormal Child Psychology, Vol. 26, no. 6, pp. 407-414, 1998.

[13] J. Richters, "Depressed mothers as informants about their children: a critical review of the evidence for distortion," Psychological Bulletin, Vol. 112, no. 3, pp. 485-499, 1992.

[14] D. P. Crowne, and D. A. Marlowe, "New scale of social desirability independent of psychopathology," Journal of Consulting Psychology, Vol. 24, no. 4, pp. 349-354, 1960.

[15] T. Kitamura, T. Suzuki, "Japanese version of Social Desirability Scale," Japanese Journal of Social Psychiatry, Vol. 9, no. 2, pp.173-180, 1986. (in Japanese)

[16] A. S. Zigmond, R. P. Snaith, "The Hospital Anxiety and Depression scale," Acta Psychiatrica Scandinavica, Vol. 67, no. 6, pp. 361-370, 1983.

[17] T. Kitamura, "Hospital Anxiety and Depression Scale," Archives of Psychiatric Diagnositics and Clinical Evaluation, Vol. 4, no. 3, pp. 371-372, 1993. (in Japanese).

[18] C. R. Cloninger, D. M. Svrakic, and T. R. Przybeck, "A psychobiological model of temperament and character," Archives of General Psychiatry, Vol. 50, no. 12, pp. 975-990, 1993. 
[19] N. A. Gillespie, C. R. Cloninger, A. C. Health, and N. G. Martin, "The genetic and environmental relationship between Cloninger's dimensions of temperament and character," Personality and Individual Differences, Vol. 35, no. 8, pp. 1931-1946, 2003.

[20] N. Kijima, E. Tanaka, N. Suzuki, H. Higuchi, and T. Kitamura, "Reliability and validity of the Japanese version of the Temperament and Character Inventory," Psychological Reports, Vol. 86, no.3, pp. 1050-1058, 2000.

[21] C. D. Spielberger, Manual for the State-Trait Anger Expression Inventory (STAXI), Psychological Assessment Resources, Odessa, FL, USA, 1988.

[22] T. Suzuki, Y. Haruki, "Ikari to junkankikei shikkan no kanrensei no kentou [The relationship between anger and circulatory disease]," The Japanese Journal of Health Psychology, Vol. 7, no. 1, PP.1-13, 1994. (in Japanese)

[23] G. Parker, H. Tupling, and L. B. Brown, "A parental bonding instrument," British Journal of Medical Psychology, Vol. 52, no. 1, pp. 1-10, 1979.

[24] T. Kitamura and T. Suzuki, "A validation study of the Parental Bonding Instrument in a Japanese population," The
Japanese Journal of Psychiatry and Neurology, Vol.47, no. 1, pp. 29-36, 1993.

[25] R. B. Cattel, "The scree test of the number of factors," Multivariate Behavioral Research, Vol. 1, pp. 245-276, 1966.

[26] J. L. Arbuckle and W. Wothke, Amos 4.0 User's Guide. SmallWaters, Chicago, IL, USA, 1955-1999, p. 153.

[27] K. Schermelleh-Engel1, H. Moosbrugger, and H. Müller. "Evaluating the fit of structural equation models: tests of significance and descriptive goodness-of-fit measures," Methods of Psychological Research Online, Vol. 8, no. 2, pp. 23-74, 2003.

[28] D. M. Fergusson, M. T. Lynskey, and L. J. Horwood, "The effect of maternal depression on maternal ratings of child behaviour," Journal of Abnormal Child Psychology, Vol. 21, pp.245-269, 1993.

[29] G. Kroes, J. W. Veerman, and E. E. J. De bruyn, "Bias in parental reports? Maternal psychopathology and the reporting of problem behavior in clinic-referred children," European Journal of Psychological Assessment, Vol. 19, no. 3, pp. 195-203, 2003. 